\title{
Carcinogenicity of kojic acid in rodents
}

\author{
Masao HIROSE $^{* 1}$, Toshio IMAI ${ }^{* 1}$, Kunitoshi MITSUMORI ${ }^{* 2}$
}

\author{
${ }^{* 1}$ Division of Pathology, National Institute of Health Sciences \\ (1-18-1 Kamiyoga, Setagaya-ku, Tokyo 158-8501, Japan) \\ ${ }^{* 2}$ Laboratory of Veterinary Pathology, Faculty of Agriculture, \\ Tokyo University of Agriculture and Technology \\ (3-5-8 Saiwai-cho, Fuchu, Tokyo 183-8509, Japan)
}

\begin{abstract}
Summary
Kojic acid, 5-hydroxy-2-(hydroxymethyl)-4-pyrone, is a secondary fungal metabolite commonly produced by Aspergillus and Penicillium. It is used in skin care product as a whitening agent, as a protectant against u.v. light, and as a food additive to prevent enzymatic browning of raw crabs and shrimps. Carcinogenicity of kojic acid in the thyroid gland of male and female $\mathrm{B} 6 \mathrm{C} 3 \mathrm{~F} 1$ mice (at doses of $1.5 \%$ and $3 \%$ in diet) and weak tumorigenicity in the liver of female mice (at a dose of $3 \%$ in diet) was demonstrated on 1998. Since that time many experiments have been conducted for the risk assessment of this compound. Kojic acid, at doses higher than $0.03 \%$ in diet, promoted rat thyroid carcinogenesis in the 2-stage carcinigenesis assay initiated with $\mathrm{N}$ bis(2-hydroxypropyl)nitrosamine (DHPN). It induced diffuse hypertrophy and focal hyperplasia in rat follicular cells without prior initiation treatment, also indicative of tumorigenicity. Since genotoxicity of kojic acid is highly suspected, mechanistic approaches are important for the regulation of this compound. Several experiments have shown serum T4 levels to be decreased and TSH levels were markedly increased by the kojic acid treatment, pointing to a negative feedback mechanism through the pituitary-thyroid axis exists. This was shown to be due to the inhibition of iodine uptake and iodine organification in the thyroid rather than to increase in the liver T4UDP-GT. Treatment with $2 \%$ kojic acid for 8 weeks in the initiation period, followed by the thyroid promoter sulfodimethoxine (SDM) failed to demonstrate any initiation activity in the rat thyroid. Therefore, it is suggested that thyroid tumors were induced through non-genotoxic mechanisms. Kojic acid induced adenomas in heterozygous $p 53-$ deficient CBA $[p 53(+/-)]$ mice, susceptible to genotoxic carcinogens, as well as in wild mice at dietary doses of $1.5 \%$ and $3 \%$ for 26 weeks, in addition to cell proliferation, which is a marker for non-genotoxic carcinogens. The incidences of neoplastic as well as preneoplastic lesions were significantly greater in the $p 53(+/-)$ than in the wild-type mice. Kojic acid at a dose of $2 \%$ in diet promoted rat hepatocarcinogenesis in the medium-term liver assay and induced GST-P positive foci without initiation treatment. Therefore, kojic acid is suggested to be a hepatocarcinogen in both mice and rats, with probable involvement of genotoxicity in addition to non-genotoxic mechanism.
\end{abstract}


Key words : kojic acid, mycotoxin, carcinogenesis, rat, mouse

\section{Introduction}

Kojic acid, 5-hydroxy-2-(hydroxymethyl)-4-pyrone, is produced by Aspergillus and Penicillium mainly belonging to the flavus-oryzae-tamarii groups. A. flavus and A. parasiticus in particular have been reported to be able to produce large amounts of kojic acid, and the A. flavus group has traditionally been used for the production of fermented foodstuffs such as miso, soy sauce and sake in Japan. Kojic acid is also used as an antiinflammatory drug and as a protectant against u.v. light. Since it inhibits mushroom tyrosinase and polyphenol oxidase, and thus blocks the formation of 3,4dihydroxyphenylalanine (DOPA) from tyrosine in the process of melanin biosynthesis, it is used as a food additive to prevent enzymatic browning of raw crabs and shrimps, and as a whitening agent in skin care products ${ }^{1)}$.

In spite of its widespread practical application, data on toxicity are very limited. In genotoxicity studies, although the DNA-repair test in Drosophila and the micronucleus test in mice proved negative, kojic acid can cause DNA breaks and clastogenic effects in cultured rat hepatocytes, and mutations in Salmonella typhimurium in the absence of S9 mixture. It induces sister chromatid exchange and chromosomal aberrations in Chinese hamster ovary cells in the presence or absence of rat S9 mixture ${ }^{2,3}$. Based on these results, it is suggested that kojic acid possesses genotoxic potential in vitro but there are only few data regarding in vivo effects.

With regard to carcinogenicity, thyroid follicular cell adenomas were significantly increased in male $(65 \%$ in $1.5 \%$, and $87 \%$ in $3.0 \%$ vs $2 \%$ in control) and female B6C3F1 mice ( $80 \%$ in $1.5 \%$ vs $2 \%$ in control) fed a diet containing 1.5 or $3 \%$ kojic acid for 20 months. The incidence of hepatocellular tumors was also significantly increased in female mice fed $3.0 \%$ kojic acid $(10 \% \text { vs } 0 \% \text { in the controls })^{4)}$.

Generally genotoxic carcinogens cannot be permitted as food additives because threshold levels cannot be determined. Therefore, for the risk assessment of kojic acid, it is of importance to examine the carcinogenic potency and underlying modes of action. In the present paper, details regarding carcinogenicity as well as toxicity data of kojic acid and its mechanisms are covered.

\section{Effects of kojic acid in a rat 2-stage thyroid carcinogenesis model and on serum thyroid related hormone and liver UDP-GT levels}

Six week old male F344 rats, obtained from Charles River Inc. (Atsugi), were housed 5 to a polycarbonated cage with white chips as bedding in an air-conditioned 
room (room temperature, $23 \pm 2{ }^{\circ} \mathrm{C}$; relative humidity, $60 \pm 5{ }^{\circ} \mathrm{C}$; a 12 light/12 dark cycle). They received a single subcutaneous injection of $2800 \mathrm{mg} / \mathrm{kg} \mathrm{N}$-bis(2hydroxypropyl)nitrosamine (DHPN, Nacalai Tesque Inc. Kyoto, Japan) as the initiation step and from 1 week thereafter were given basal diet (CRF-1, Oriental Yeast Co. Ltd., Tokyo) containing 0, 2 or $4 \%$ kojic acid (Nagase Biochemical Co. Tokyo, Japan) for 4 or 12 weeks and then subjected to autopsy for histopathological examination. After two weeks of kojic acid treatment, subgroups of 3 animals each were killed for serum thyroid related hormone and liver T4-uridine diphosphate glucuronosyltransferase (UDP-GT) assays. Serum T3 and T4 were measured by Micro particle enzyme and Fluorescence Polarization Immunoassays, using a T3- and a T4-Dainapack (Abbott Laboratories, North Chicago, U.S.A.), and serum TSH with an NIADDK radio immunoassay kit (RP2) supplied by Dr. A. F. Parlow of the Pituitary and Antisera Center, Harbor-UCLA Medical Center (CA, U.S.A.). UDP-GT activity was determined by measuring the production of T4-glucuronide as previously described ${ }^{5)}$ with a minor modification.

Incidences of thyroid follicular cell tumors were increased at a dose of $2 \%$ at weeks $4(60 \%$ vs. $0 \%$ in control group) and $12(100 \%$ vs. $0 \%)$. In addition, during the experimental period, serum T4 and T3 levels were significantly decreased, and the TSH levels were increased at doses 2 and $4 \%$. The liver T4-UDP-GT levels were tended to increase dose-dependently, but without statistical difference (data not shown) ${ }^{6.7)}$. These data indicate that kojic acid clearly promotes thyroid carcinogenesis, and increase in the TSH through negative feedback in the pituitary-thyroid axis, rather than alteration in UDP-GT, is responsible for this action.

\section{Effects of kojic acid on iodine uptake and organification in the rat thyroid gland}

To investigate further mechanisms of negative feedback in the pituitary-thyroid axis, male F344 rats, 8 rats per each group, were given powdered basal diet containing 0 $\%, 0.03 \%, 0.125 \%, 0.5 \%$ or $2 \%$ kojic acid for 4 weeks. Blood was collected from the abdominal aorta of 5 animals of each group under ether anesthesia for hormone assays followed by autopsy for histopathological examination. Amarex-MT3 and Amarex-MT4 assay kits (Oso Clinical Diagnostic Co. Tokyo) were employed to determine serum T3 and T4 concentrations. Serum TSH was measured with NIADDK reagents following the recommended protocol. The remainder of the rats were sacrificed for measurement of ${ }^{125} \mathrm{I}$ uptake and its organification in the thyroid ${ }^{8)}$ at the end of experiment.

The thyroid ${ }^{125}$ I uptake was significantly decreased in the groups receiving $0.03 \%$ or more. In addition, significant reductions of organic formation of iodine and serum T3 and T4 levels was observed in the $2 \%$ kojic acid group along with pronounced elevation of serum TSH. Histopathological changes in the follicular epithelium were also observed in the groups given $0.03 \%$ or more (Table 1$)^{9,10}$. These results indicate that inhibitions 
Table 1. Serum thyroid hormone levels, ${ }^{125}$ I uptake and organic ${ }^{125}$ I formation ratio in the thyroid glands of rats fed kojic acid for 4 weeks.

\begin{tabular}{|c|c|c|c|c|c|c|c|}
\hline \multirow{2}{*}{$\begin{array}{l}\text { Dose } \\
(\%)\end{array}$} & \multirow{2}{*}{$\begin{array}{l}\text { No. of } \\
\text { rats }\end{array}$} & \multicolumn{3}{|c|}{ Thyroid hormones } & \multicolumn{2}{|c|}{${ }^{125}$ I uptake } & \multirow{2}{*}{$\begin{array}{l}\text { Organic }{ }^{125} I \\
\text { formation ratio }\end{array}$} \\
\hline & & $\mathrm{T} 3(\mu \mathrm{g} / \mathrm{L})$ & $\mathrm{T} 4 \quad(\mu \mathrm{g} / \mathrm{dl})$ & $\mathrm{TSH}(\mu \mathrm{g} / \mathrm{L})$ & $\begin{array}{c}10^{3} \mathrm{cpm} \\
/ \mathrm{mg} \text { protein }\end{array}$ & $\%$ control & \\
\hline 0 & 5 & $0.61 \pm 0.09$ & $3.7 \pm 0.3$ & $6.8 \pm 0.7$ & $25.6 \pm 3.7$ & 100 & $73.5 \pm 5.1$ \\
\hline 0.03 & 5 & $0.62 \pm 0.06$ & $3.5 \pm 0.3$ & $5.9 \pm 1.1$ & $15.6 \pm 3.4^{* *}$ & $60.9 \pm 13.4$ & $76.0 \pm 1.3$ \\
\hline 0.125 & 5 & $0.58 \pm 0.07$ & $3.3 \pm 0.1$ & $7.2 \pm 0.4$ & $11.9 \pm 1.1^{* *}$ & $46.5 \pm 4.1$ & $73.2 \pm 2.7$ \\
\hline 0.5 & 5 & $0.72 \pm 0.06$ & $3.4 \pm 0.3$ & $8.8 \pm 2.3$ & $8.0 \pm 2.6^{* *}$ & $31.1 \pm 10.3$ & $74.2 \pm 4.9$ \\
\hline 2 & 5 & $0.36 \pm 0.13^{* *}$ & ${ }^{*} 1.7 \pm 0.4^{* *}$ & $29.1 \pm 10.4^{*}$ & $3.9 \pm 0.2^{* *}$ & $15.1 \pm 0.7$ & $39.7 \pm 10.7^{* *}$ \\
\hline
\end{tabular}

${ }^{*} \mathrm{p}<0.05,{ }^{* *} \mathrm{p}<0.01$ vs $0 \%$ group

of iodine uptake as well as organification of iodine play an important role for the prolonged serum TSH stimulation, promotion of carcinogenesis and induction of proliferative lesions.

\section{Dose-response study of kojic acid in the rat 2-stage thyroid carcinogenesis model}

To evaluate the threshold dose of kojic acid for the promotion of thyroid carcinogenesis, groups of 10 male F344 rats were initiated with DHPN $(2000 \mathrm{mg} / \mathrm{kg}$ body wt., single s.c. injection) and, starting 1 week later, were given powdered basal diet containing $0 \%, 0.002 \%, 0.008 \%, 0.03 \%, 0.125 \%, 0.5 \%$ or $2 \%$ kojic acid for 20 weeks. Additionally, three groups without DHPN initiation received basal diet, or diet containing $0.5 \%$ or $2 \%$ kojic acid for 20 weeks.

In the DHPN-initiated groups, the incidences of hypertrophy/diffuse hyperplasias, focal hyperplasias, adenomas and adenocarcinomas were increased in the $0.03 \%$ or more, $0.125 \%$ or more, $0.5 \%$ or more and $2 \%$ groups, respectively. In the groups without DHPN initiation, hyperprophy/diffuse hyperplasia was increased in the $0.5 \%$ and $2 \%$ groups and focal hyperplasia was observed in 1 of 9 rats in the $2 \%$ group (Table $2)^{11}$. These results suggest that the no-observed-adverse effect level for the thyroid tumor-promoting effect of kojic acid is $0.008 \%$ under the present experimental conditions, and that kojic acid possesses weak tumorigenic activity in rats.

\section{Initiation assay of kojic acid in the rat 2-stage thyroid carcinogenesis model}

To assess the contribution of genotoxicity in the induction of thyroid proliferative lesions, groups of 10 male F344 rats were treated with $0,0.02,0.2$ or $2 \%$ kojic acid for 8 weeks in the initiation period, followed by sulfadimethoxine (SDM), a typical thyroid promoter, at a dose of $0.1 \%$ in drinking water for further 23 weeks. As a positive 
Table 2. Incidence of thyroid proliferative lesions in rats fed various doses of kojic acid with or without initiation pretreatment.

\begin{tabular}{|c|c|c|c|c|c|c|}
\hline \multicolumn{2}{|c|}{ Treatment } & \multirow{2}{*}{$\begin{array}{l}\text { No. of } \\
\text { rats }\end{array}$} & \multirow{2}{*}{$\begin{array}{l}\text { Hypertrophy } \\
\text { /hyperplasia }\end{array}$} & \multirow{2}{*}{$\begin{array}{c}\text { Focal } \\
\text { hyperplasia }\end{array}$} & \multirow[b]{2}{*}{ Adenoma } & \multirow{2}{*}{$\begin{array}{l}\text { Adeno- } \\
\text { carcinoma }\end{array}$} \\
\hline DHPN & $\begin{array}{c}\text { Dose of } \\
\text { kojic acid(\%) }\end{array}$ & & & & & \\
\hline \multirow{7}{*}{+} & 0 & 10 & 0 & 0 & 10 & 0 \\
\hline & 0.002 & 10 & 0 & 0 & 0 & 0 \\
\hline & 0.008 & 10 & 0 & 0 & 0 & 0 \\
\hline & 0.03 & 10 & 4 & 0 & 0 & 0 \\
\hline & 0.125 & 10 & $10^{* *}$ & $5^{*}$ & 0 & 0 \\
\hline & 0.5 & 10 & $10^{* *}$ & $10^{* *}$ & $7^{* *}$ & 0 \\
\hline & 2 & 8 & $8^{* *}$ & $8^{* *}$ & $8^{* *}$ & $6^{* *}$ \\
\hline \multirow{3}{*}{ - } & 0 & 5 & 0 & 0 & 0 & 0 \\
\hline & 0.5 & 5 & $5^{* *}$ & 0 & 0 & 0 \\
\hline & 2 & 9 & $9^{* *}$ & 1 & 0 & 0 \\
\hline
\end{tabular}

${ }^{*} \mathrm{p}<0.05,{ }^{* *} \mathrm{p}<0.01$ vs the respective $0 \%$ group

control, $700 \mathrm{mg} / \mathrm{kg}$ bw of DHPN was subcutaneously injected 4 times during the initial 8 weeks instead of kojic acid. An additional group was treated with $2 \%$ kojic acid for 8 weeks then drinking water alone for 23 weeks.

Histopathological analysis showed no inter-group statistical differences in the incidences and multiplicities of focal hyperplasias among the SDM-treated groups (10 $\%-40 \%$ in incidence and $0.1 \pm 0.3-0.5 \pm 0.7 /$ rat in multiplicity), except with DHPN, when the incidence of focal hyperplasias (100\% vs $20 \%$ in control group), adenomas and adenocarcinomas (100\% vs $0 \%$ ) were significantly increased (Table 3). These results indicate that kojic acid does not have initiating activity for thyroid carcinogenesis

Table 3. Incidence and multiplicity data for thyroid proliferative lesions in rats initiated with kojic acid given SDM.

\begin{tabular}{|c|c|c|c|c|c|c|c|c|}
\hline \multirow{2}{*}{\multicolumn{2}{|c|}{ Treatment }} & \multirow{2}{*}{$\begin{array}{c}\text { No. of } \\
\text { rats }\end{array}$} & \multicolumn{2}{|c|}{ Focal hyperplasia } & \multicolumn{2}{|c|}{ Adenoma } & \multicolumn{2}{|c|}{ Adenocarcinoma } \\
\hline & & & Incidence & No./rat & Incidence & No./rat & Incidence & No./rat \\
\hline Basal diet & $\rightarrow 0.1 \% \mathrm{SDM}$ & 10 & 2 & $0.3 \pm 0.7$ & 0 & 0 & 0 & 0 \\
\hline DHPN & $\rightarrow 0.1 \%$ SDM & 9 & $9^{*}$ & $15.0 \pm 3.9^{*}$ & $9^{*}$ & $6.6 \pm 2.4$ & $9^{*}$ & $3.8 \pm 2.2$ \\
\hline $\mathrm{KA}(0.02 \%)$ & $\rightarrow 0.1 \%$ SDM & 10 & 1 & $0.1 \pm 0.3$ & 0 & 0 & 0 & 0 \\
\hline $\mathrm{KA}(0.2 \%)$ & $\rightarrow 0.1 \%$ SDM & 10 & 2 & $0.2 \pm 0.4$ & 0 & 0 & 0 & 0 \\
\hline $\mathrm{KA}(2 \%)$ & $\rightarrow 0.1 \% \mathrm{SDM}$ & 10 & 4 & $0.5 \pm 0.7$ & 0 & 0 & 0 & 0 \\
\hline $\mathrm{KA}(2 \%)$ & & 10 & 0 & 0 & 0 & 0 & 0 & 0 \\
\hline
\end{tabular}

SDM: sulfadimethoxine

${ }^{*} \mathrm{p}<0.05,{ }^{* *} \mathrm{p}<0.01$ vs $0.1 \%$ SDM alone group 
under the present experimental conditions employed.

\section{Effects of kojic acid in p53 knockout mice}

This experiment was performed to confirm the carcinogenicity of kojic acid using 67 week-old p53 heterozygous knock out CBA mice (Oriental Yeast Co., Tokyo), which are susceptible for genotoxic carcinogens. Heterozygous $p 53$ deficient CBA $[p 53(+/-)]$ male and wild-type littermates $[p 53(+/+)]$ were fed diet containing $0,1.5$ and $3 \%$ kojic acid for 26 weeks and then killed for the histopathological examination.

In the thyroid gland, kojic acid induced diffuse follicular hypertrophy and hyperplasia in both $p 53(+/-)$ and $p 53(+/+)$ mice, but tumors were not found. In the liver, the incidence of altered hepatocellular foci was significantly increased at the 1.5 and $3 \%$ doses in $p 53(+/-)$ and $1.5 \%$ in $p 53(+/+)$ mice, and that of hepatocellular adenomas was increased at 1.5 and $3 \%$ in $p 53(+/-)$ and $3 \%$ in $p 53(+/+)$ mice. P53(+/-) mice appeared to be more susceptible in terms of the tumorigenicity of kojic acid with a greater prevalence of hepatic proliferative lesions (Table 4). In addition, incidence of focal necrosis and the number of PCNA-positive hepatocytes $(5.0 \pm 3.6$ vs. $1.7 \pm 1.1$ in control group) were increased in $p 53(+/-)$ mice fed kojic acid ${ }^{12}$. The results confirmed tumorigenic potential of kojic acid in the mouse liver, but not thyroid follicular epithelial cells in CBA mice, and suggested a possible contribution of genotoxicity in addition to cell proliferation in hepatocellular tumor development.

Table 4. Histopathological findings for livers of mice treated with kojic acid for 26 weeks.

\begin{tabular}{|c|c|c|c|c|c|c|c|c|}
\hline \multirow{2}{*}{ Mice } & \multirow{2}{*}{$\begin{array}{c}\text { Dose } \\
(\%)\end{array}$} & \multirow{2}{*}{$\begin{array}{c}\text { No. of } \\
\text { mice }\end{array}$} & \multirow{2}{*}{$\begin{array}{l}\text { Inflammatory } \\
\text { cell infiltration }\end{array}$} & \multirow{2}{*}{$\begin{array}{c}\text { Focal } \\
\text { necrosis }\end{array}$} & \multicolumn{2}{|c|}{ Altered cell foci } & \multicolumn{2}{|c|}{ Adenoma } \\
\hline & & & & & Incidence & No./slide & Incidence & No./slide \\
\hline \multirow{3}{*}{$p 53(+/-)$} & 0 & 7 & 0 & 0 & 0 & 0 & 0 & 0 \\
\hline & 1.5 & 10 & 2 & 3 & $5^{*}$ & $0.9 \pm 1.1$ & $\left\lceil 7^{* *}\right.$ & $1.2 \pm 1.1$ \\
\hline & 3 & 10 & 1 & 2 & $-8^{* *}$ & $0.9 \pm 0.6$ & $5^{*}$ & $0.6 \pm 0.7$ \\
\hline \multirow{3}{*}{$p 53(+/+)$} & 0 & 10 & 2 & 1 & \#\# & 0 & 0 & 0 \\
\hline & 1.5 & 12 & 2 & 1 & $5^{*}$ & $0.5 \pm 0.7$ & $\leftarrow 2$ & $0.2 \pm 0.4$ \\
\hline & 3 & 12 & 3 & 3 & -2 & $0.2 \pm 0.4$ & $5^{*}$ & $0.7 \pm 0.9$ \\
\hline
\end{tabular}

${ }^{*} \mathrm{p}<0.05,{ }^{* *} \mathrm{p}<0.01$ vs. respective $0 \%$ group $\# \mathrm{p}<0.05, \# \mathrm{p}<0.01$ among $p 53(+/-)$ and $p 53(+/+)$ groups 


\section{Promotion effects of kojic acid in a rat medium-term liver carcinogenesis model}

To confirm the tumorigenic activity of kojic acid in rats, medium-term liver bioassay ${ }^{13)}$ was applied. Groups of 25 male F344 rats, at the age of 6 weeks, were given a single intra-peritoneal injection of $200 \mathrm{mg} / \mathrm{kg}$ bw of diethylnitrosamine (DEN) as an initiator. Starting 2 weeks thereafter, they were fed powdered diet containing $0 \%, 0.125$ $\%, 0.5 \%$ or $2 \%$ kojic acid (Alps Pharmaceutical Ind. Co. Ltd., Gifu) for 6 weeks. After one week of kojic acid treatment, rats were subjected $2 / 3$ partial hepatectomy. Animals were killed at week 8 , their livers were fixed with cold acetone, sectioned and routinely stained immunohistochemically with anti-glutathione S-transferase placental form (GSTP) antibody. The number and area of GST-P positive foci larger than $0.2 \mathrm{~mm}$ in diameter were determined.

Values for both parameters were significantly increased only in the group fed $2 \%$ kojic acid (Table 5).

Table 5. Quantitative analysis of liver GST-P positive foci in the rat medium-term liver bioassay.

\begin{tabular}{cccc}
\hline $\begin{array}{c}\text { Dose } \\
(\%)\end{array}$ & $\begin{array}{c}\text { No. of } \\
\text { rats }\end{array}$ & $\begin{array}{c}\text { Number } \\
\left(\text { No. } / \mathrm{cm}^{2}\right)\end{array}$ & $\begin{array}{c}\text { Area } \\
\left(\mathrm{mm}^{2} / \mathrm{cm}^{2}\right)\end{array}$ \\
\hline 0 & 18 & $8.42 \pm 2.69$ & $0.77 \pm 0.34$ \\
0.125 & 19 & $8.17 \pm 2.15$ & $0.65 \pm 0.23$ \\
0.5 & 23 & $8.49 \pm 2.33$ & $0.68 \pm 0.25$ \\
2 & 24 & $16.92 \pm 3.18^{* *}$ & $1.62 \pm 0.39 * *$ \\
\hline
\end{tabular}

${ }^{* *} \mathrm{p}<0.01$ vs the $0 \%$ group

In another experiment, groups of 20 6-week-old male F344 rats were treated continuously with $0,0.5$ or $2 \%$ kojic acid (Alps Pharmaceutical Ind. Co. Ltd., Gifu) in the diet for 20 weeks without initiation treatment, then sacrificed and acetone-fixed liver tissues were processes for the quantitative analysis of the GST-P positive foci. Foci consisting of 5 cells or more in cross-section were counted because the sizes of foci were generally small.

The average number and area of foci were significantly increased only in animals fed $2 \%$ kojic acid (No.: $0.65 \pm 0.57 / \mathrm{cm}^{2}$; area: $48.0 \pm 54.8 \mu \mathrm{m}^{2} / \mathrm{mm}^{2}$, vs. No.: $0.16 \pm$ $0.28 / \mathrm{cm}^{2}$; area: $6.2 \pm 11.68 \mu \mathrm{m}^{2} / \mathrm{mm}^{2}$ in control group), providing further evidence that kojic acid might be a weak hepatocarcinogen in rats. 


\section{Discussion}

Kojic acid had been approved as a food additive as well as for use in cosmetics in spite of the absence of long-term carcinogenicity study data, since it was long been accepted to be a naturally occurring compound without risk of toxicity. However, evaluation of the risk of kojic acid demonstrated mutagenicity in various mutagenesis assays and therefore carcinogenicity was assessed using mice and the incidence of thyroid adenomas was found to be significantly increased in both males and females, as well as the incidence of hepatocellular tumors, slightly but significantly, in females. In a 2-stage rat thyroid carcinogenesis model after initiation with DHPN, kojic acid dosedependently promoted thyroid carcinogenesis at doses more than $0.03 \%$ in diet. The treatment with decreased the serum T3 and T4 levels, but increased TSH pronouncedly. Although the liver T4-UDP-GT activity, which is responsible for T4 clearance in the liver, was not enhanced, iodine uptake and organification of iodine in the thyroid were clearly inhibited. Similar findings were obtained after repeated oral ${ }^{14)}$ or single administration of kojic acid in rats ${ }^{15)}$, suggesting that kojic acid enhances thyroid carcinogenesis and induces development of proliferative lesions by stimulating negative feedback through the pituitary-thyroid axis. Lack of initiation activity in the rat 2-stage carcinogenesis model, and a lack of DNA-adducts and oxidative stress as evaluated by the ${ }^{32} \mathrm{P}$-postlabeling assay and formation of $8-\mathrm{OHdG}$ in the thyroid tissue, respectively (unpublished data), indicate that epigenetic rather than genotoxic mechanisms are operating in the thyroid carcinogenesis of kojic acid.

In the liver, the compound was confirmed to induce hepatocellular tumors in male $\mathrm{p} 53(+/-)$ and to a lesser extent $\mathrm{p} 53(+/+)$ mice. The $\mathrm{p} 53(+/-)$ mice derived from $\mathrm{C} 57 \mathrm{BL} / 6$ or CBA origins have been recognized as a useful model to detect carcinogens, particularly genotoxic examples, within a short period ${ }^{16)}$. Taking the genotoxic property of kojic acid in several mutagenesis assays into account, in addition to cell proliferation, genotoxic mechanism cannot be ruled out in the induction of mouse liver tumors. In rats, kojic acid promoted hepatocarcinogenesis in a 2-stage carcinogenesis model with DHPN as the initiator (unpublished data), as well as in the medium-term liver carcinogenesis model at a dose of $2 \%$ in diet. Moreover, preneoplastic GST-P positive foci were slightly, but significantly increased in rats fed $2 \%$ kojic acid for 20 weeks without initiation treatment. Sequential observation of rats fed $2 \%$ kojic acid revealed that bromodeoxyuridine ( $\mathrm{BrdU})$ labeling index in the hepatocytes to be significantly increased at days 3 and 7 but to return to the control level at day 28, but 8-OHdG was not elevated at any time point (unpublished data). These results indicate that kojic acid is a cell proliferation mediated promoter of hepatocarcinogenesis and also a weak hepatocarcinogen in rats. Although Japanese government already decided to ban the use 
of kojic acid as a food additive, further experiments to elucidate the contribution of genotoxicity in the development of hepatocarcinogenesis and the effect of kojic acid on the skin carcinogenesis are needed for the risk assessment regarding skin care use.

These works were supported by Health and Labour Sciences Research Grants and Grant-in-Aids for Research on Food Sanitation from the Ministry of Health, Labour and Welfare of Japan.

\section{References}

1 ) Burdock, G.A., Soni, M.G., Carabin, I.G.: Reg Toxicol. Pharmacol., 33, 80-101 (2001)

2 ) Obana, H., Nishimune, T.: Jpn. J. Toxicol. Environ. Health, 39, 577-581 (1993)

3 ) IARC: IARC Monographs on the Evaluation of Carcinogenic Risks to Humans, 79, 607-618 (2001)

4 ) Fujimoto, F., Watanabe, H., Nakatani, T., Roy, G., Ito, A.: Fd. Chem. Toxicol., 36, 697-703 (1998)

5 ) Comer, C.P., Chengelis, C.P., Levin, S, Kotsonis, F.: Toxicol. Appl. Pharmacol., 80, 427-436 (1985)

6 ) Mitsumori, K., Onodera, H., Takahashi, M., Funakoshi, T., Tamura, T., Yasuhara, K., Takegawa, K., Takahashi, M.: Carcinogenesis, 20, 173-176 (1999)

7 ) Tamura, T., Mitsumori, K., Onodera, H., Takahashi, M., Funakoshi, T., Yasuhara, K., Takegawa, K., Takagi, H., Hirose, M.: J. Toxicol. Sci., 24, 145-155 (1999)

8 ) Okuno, Y., Kunimatsu, T., Takahashi, K., Watanabe, T., Takahashi, M., Takegawa, K., Onodera, H., Mitsumori, K.: J. Toxicol. Pathol., 9, 385-390 (1996)

9 ) Fujimoto, N., Onodera, H., Mitsumori, K., Tamura, T., Maruyama, S., Ito, A.: Carcinogenesis, 20, 1567-1571 (1999)

10) Tamura, T., Mitsumori, K., Onodera, H., Fujimoto, N., Yasuhara, K., Takegawa, K., Takahashi, M.: Toxicol. Sci., 47, 170-175 (1999)

11) Tamura, T., Mitsumori, K., Onodera, H., Fujimoto, N., Yasuhara, K., Takegawa, K., Takagi, H., Hirose, M.: J. Toxicol. Sci., 26, 85-94 (2001)

12) Takizawa, T., Mitsumori, K., Tamura, T., Nasu, M., Ueda, M., Imai, T., Hirose, M.: Toxicol. Sci., 73, 287-293 (2003)

13) Shirai, T.: Invest. Toxicol. Pathol., 25, 453-460 (1997)

14) Higa, Y., Ohkubo, A., Kitajima, S., Hatori, A., Kariya, K.: J. Toxicol. Sci., 25, 167-175 (2000)

15) Higa, Y., Ohkubo, A., Kitajima, S., Moriyasu, M., kariya, K: J. Toxicol. Sci., 27, 423-431 (2000)

16) Gulezian, D., Jacobson-Kram, D., McCullough, C.B., Olson, H., Recio, L., Robinson D., Storer, R., Tennant, R., Ward, J.M., Neumann, D.A.: Toxicol. Pathol., 28, 482-499 (2000) 